\title{
Power Quality Analysis of Grid-Connected Photovoltaic System with Adjustable Speed Drives
}

\author{
M. Anwari, Member, IEEE, M. Imran Hamid, M. I. M. Rashid, and Taufik, Senior Member, IEEE
}

\begin{abstract}
This paper presents power quality analysis of a distributed generation system consisting of Photovoltaic (PV) Inverter system as the renewable source connected to a network of Adjustable Speed Drives (ASDs) as the load. A small-scale laboratory consists of Photovoltaic, Inverter, ASDs and loads system was setup. Two power supplies from PV and grid were connected to two ASDs which powered two separate induction motors. Load of motor 1 was fixed while load of motor 2 was varied. In the experiment, both energy supplies from the grid and photovoltaic system were connected to the loads. Measurements have been done at both side of power transformer to analyze power quality in the system.
\end{abstract}

Index Terms-Grid-connected PV, Adjustable Speed Drives, Power Quality.

\section{INTRODUCTION}

$\mathrm{R}$ enewable energy is no longer just an option nowadays. The renewable energy plays an important role in our live due to rise demand for electrical power. Photovoltaic is one of the renewable energy that has been used for about decade ago [1]. Photovoltaic or known as solar energy is a renewable resource that is vast and is locally available. It is a clean energy source that allows for local energy independence. The sun's energy flow reaching the earth is typically about 1,000 Watts per square meter $(\mathrm{W} / \mathrm{m} 2)$, although ease of use varies with location and time of year [2].

Photovoltaic produce DC voltage to the load. The voltage can be converting to $\mathrm{AC}$ by using $\mathrm{DC}-\mathrm{AC}$ converter which is commonly known as inverter. The inverter conversion process with power electronics is generally known as the switchedmode inversion. One major application of switched-mode is Adjustable Speed Drive (ASD) [3]. ASD is an electronic device that controls the rotational speed of motor-driven

This work was supported by the Malaysia Ministry of Science, Technology and Innovation under Science Fund Grant 03-01-06-SF0205.

M. Anwari is with the Department of Energy Conversion Engineering, Faculty of Electrical Engineering, Universiti Teknologi Malaysia, 81310 UTM Skudai, Johor, Malaysia (e-mail: makbul@ieee.org).

M. I. Hamid is a PhD student at the Faculty of Electrical Engineering, Universiti Teknologi Malaysia, 81310 UTM Skudai, Johor, Malaysia (email: imrandgmasse@yahoo.com).

M. I. M. Rashid is a Master Course student at the Faculty of Electrical Engineering, Universiti Teknologi Malaysia, 81310 UTM Skudai, Johor, Malaysia (email: ikram_amd@yahoo.com).

Taufik is with the Electrical Engineering Department, Cal Poly State University, San Luis Obispo, CA 93407, USA (email: taufik@calpoly.edu). equipment such as fans, pumps, and compressors. By ensuring that the motor's speed is accurately matched to the load placed on the motor, an ASD helps to save energy. Speed control is achieved by adjusting the frequency of the voltage applied to the motor. That why they also called ASDs as Variable Frequency Drives (VFDs). ASD is becoming a significant load component for power distribution systems. However, there are some cons to ASD systems, mainly the harmonics created by the power electronic components in the ASD. Harmonics are created by the switching system of the power electronic circuit inside the drive and can cause damage to power equipment on the utility side and sensitive loads on the customer side. Because of this, the Institute of Electrical and Electronic Engineers (IEEE) has developed standards for the amount of harmonic distortion a customer's load can inject back into the utility lines. To conform to this relatively new established guideline, it is a common practice nowadays for VFD systems to have line filters installed before them to reduce distortion caused by the VFDs back to the line. Doing so will therefore maintain a degree of power quality at the distribution level. More importantly, these line filters will also prevent the harmonic distortion to propagate back and further up at the transmission level [4].

The effects of harmonics on voltage stability of power systems and how adjustable speed drives affect these harmonics have been studied [5]. This paper also comprises that addresses several issues related to the effect of ASDs on distribution systems: 1) the influence of harmonics on the increased power, and 2) the influence of harmonics on the motor load in voltage stability studies.

In this paper, Photovoltaic connected to grid is used as power supply to the load. ASD as load to this system, two motor are used as real load and connected to two ASD as controller. A laboratory setup was established to perform the measurement. Data obtained from power quality of PV Inverter -Adjustable Speed Drive System study would provide the preliminary understanding on how to determine and identify optimum operating condition based on the worst and best case operating scenarios.

\section{LABORATORY SETUP}

The experimental setup of this research consists of two power supplies. The first source of energy supply to the drive was from the grid - transformer system. The second source of energy supply to the drive was from the photovoltaic inverter system. Those two power supplies were connected to 
two adjustable speed drives of $0.5 \mathrm{hp}$ and $1.5 \mathrm{hp}$. Each of adjustable speed drives (ASD) powered two separate induction motors. $0.5 \mathrm{hp} \mathrm{ASD}$ powered $0.25 \mathrm{hp}$ induction motor that was referred as motor 1 whereas $1.5 \mathrm{hp}$ ASD powered $2 \mathrm{hp}$ induction motor that was referred as motor 2. Load of motor 1 was fixed at $25 \%$ torque and load of motor 2 was varied for $0 \%$ to $\leq 50 \%$ torque.

In this research project, there were two types of experiment that have been carried out. Figure 1 shows the block diagram of laboratory setup. They are simplified diagram of the system indicating the labeling convention of the data and graphs. All experiments were conducted under room temperature. Figure 1 shows energy supply from grid and photovoltaic system have been used

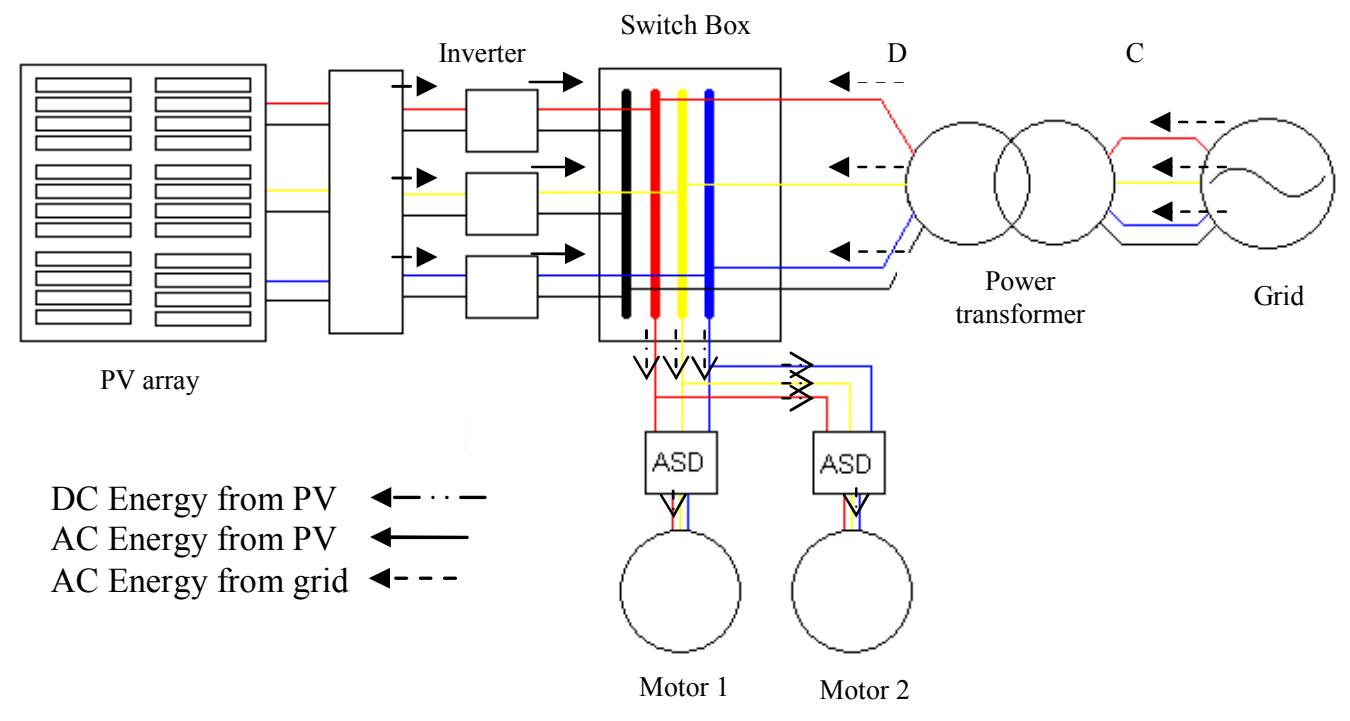

Fig. 1. Experimental setup; PV Inverter system with adjustable speed drives are connected to grid.

The experiment that was carried out in the laboratory is shown in Figure 1 in which used both energy supplies from grid and photovoltaic system were connected to the loads. Measurements were recorded at both side of power transformer at point $\mathrm{C}$, and $\mathrm{D}$ to analyze power quality in these systems. Figure 2 shows the laboratory setup for the measurement.

In conducting the experiment, frequency of the system and load motor 2 (Carpanelli) were varied from $40 \mathrm{~Hz}$ to $70 \mathrm{~Hz}$ and 0 to $\leq 50 \%$ of load whereas load motor 1 (Feedback) was fixed at $25 \%$ of load. Each time data collection was completed, the data was compiled into graphs to monitor the difference of harmonics distortion based on location and percentage of the rated load.

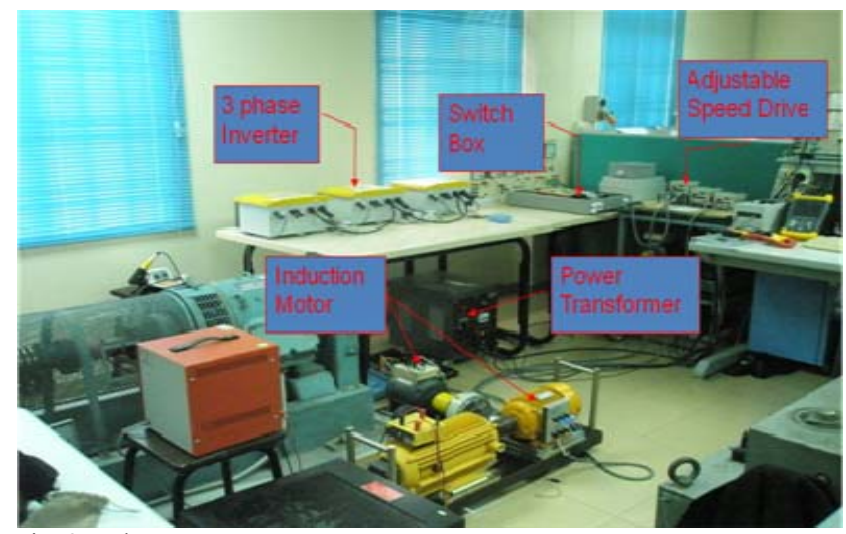

Fig. 2. Laboratory setup Table 1 lists the equipments that have been installed in the laboratory:

TABLE I

EQUIPMENTS USED FOR LABORATORY SETUP

\begin{tabular}{|c|c|c|}
\hline Unit & Equipment & Rating \\
\hline 24 modules & Photovoltaic(Amorphous Silicon) & $5 \mathrm{~kW}$ peak, $\approx 1 \mathrm{~kW}$ \\
\hline 3 & Inverter(Sunny Boy) & $0.7 \mathrm{~kW}, 3 \mathrm{~A}, 230 \mathrm{~V}_{\mathrm{ac}}$ \\
\hline$\overline{1}$ & Power transformer & $3 \mathrm{kVA}$ \\
\hline 2 & ASD(Omron Varispeed V7) & $1.1 \mathrm{~kW} \& 0.3 \mathrm{~kW}$ \\
\hline 1 & Induction motor1 (Feedback) & $1 / 4 \mathrm{Hp}$ \\
\hline 1 & Break System & $24 \mathrm{~V}, 1.24 \mathrm{~A}, 25 \mathrm{Nm}$ \\
\hline 1 & Torque Adjustable(TAL-100V) & $100 \mathrm{~V}$ \\
\hline 1 & Induction motor2 (Carpanelli) & $2 \mathrm{Hp}$ \\
\hline 1 & Resistive load bank(NE 7026) & $3 \mathrm{Kw}$ \\
\hline 1 & Load measurement(De Lorenzo) & $0.75 \mathrm{~kW}, 3.4 \mathrm{~A}$ \\
\hline
\end{tabular}




\section{RESULTS AND DISCUSSION}

Figures 3 to 14 show trends in THDv and THDi for different M2 torque load percentages at both side power transformer which in point $\mathrm{C}$ for primary and $\mathrm{D}$ for secondary.

\section{A. Analysis of Voltage Distortion}

In this experiment, THDv for PV-grid connection is shown in graphs as in figure 3, 5, 7, 9, 11, and 13. THDv value for PV- grid connection is higher than THDv grid connection for all different frequency. This evidence is shown in THDv graphs for this experiment when compare to previous experiment. This phenomenon happened when photovoltaic system was implementing in grid system.

\section{B. Analysis of Current Distortion}

The THDi for PV-grid connection is shown in figure 4, 6 , $8,10,12$, and 14. THDi value with respect to PV-grid connection is higher and not consistence rather than THDi for grid connection for all different frequency. This evidence is shown in THDi graphs of this experiment when compared to previous experiment. This phenomenon happened when photovoltaic system was implemented in grid system. The highest THDi or worst case happened when the real power in this system nearly changed the polarity from positive to negative or negative to positive. The negative and positive real power indicates energy supply from PV and grid, respectively. The lowest THDi which is the best case happened when smaller negative value of real power was recorded. Since PV produced smaller negative value compared to grid, it can be concluded that supply from PV has smallest THDi.

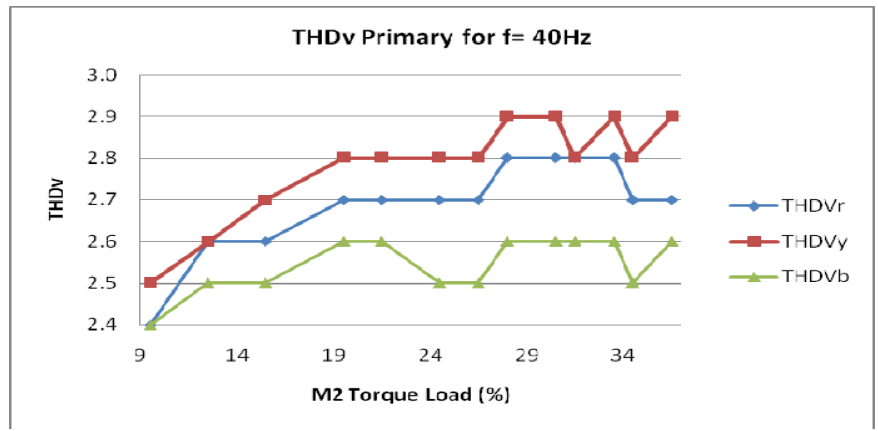

Fig. 3. THDi vs M2 torque load at point $\mathrm{C}$ for M1 at $25 \%$ of rated torque.

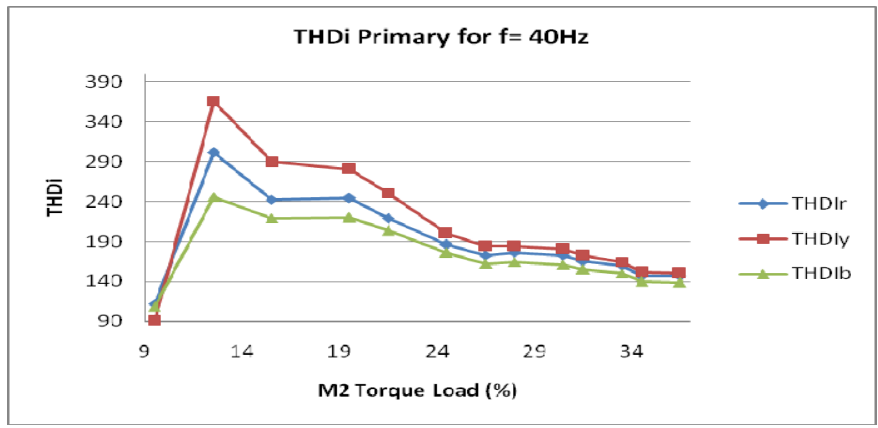

Fig. 4. THDi vs M2 torque load at point $\mathrm{C}$ for $\mathrm{M} 1$ at $25 \%$ of rated torque.

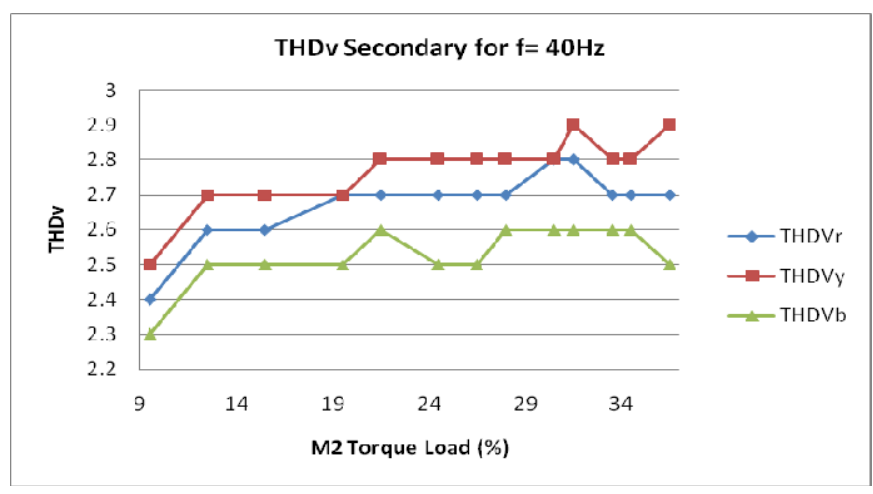

Fig. 5. THDi vs M2 torque load at point D for M1 at $25 \%$ of rated torque.

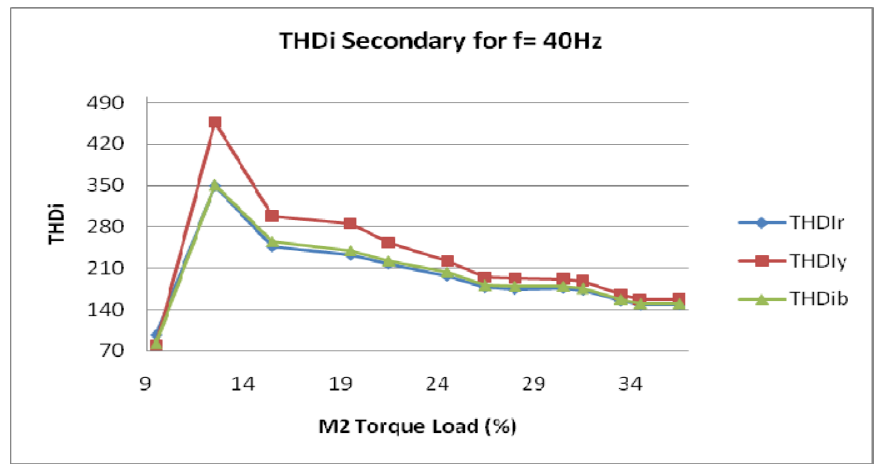

Fig. 6. THDi vs M2 torque load at point D for M1 at $25 \%$ of rated torque.

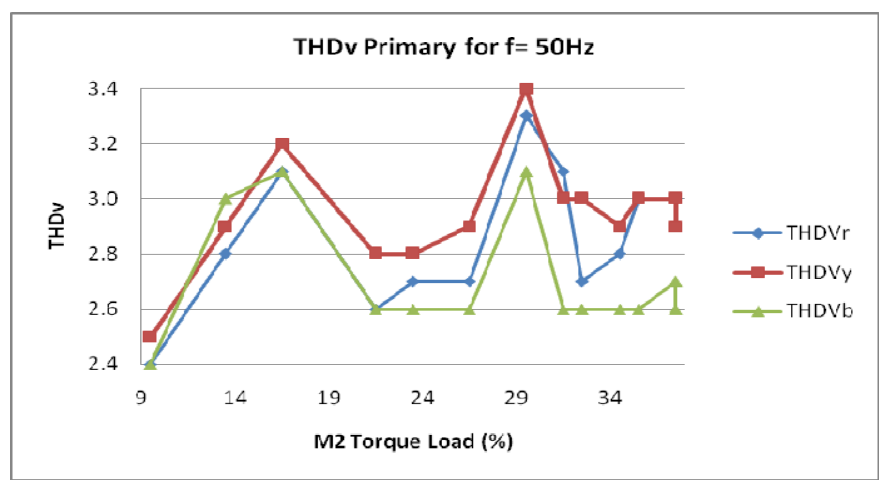

Fig. 7. THDi vs M2 torque load at point $\mathrm{C}$ for $\mathrm{M} 1$ at $25 \%$ of rated torque.

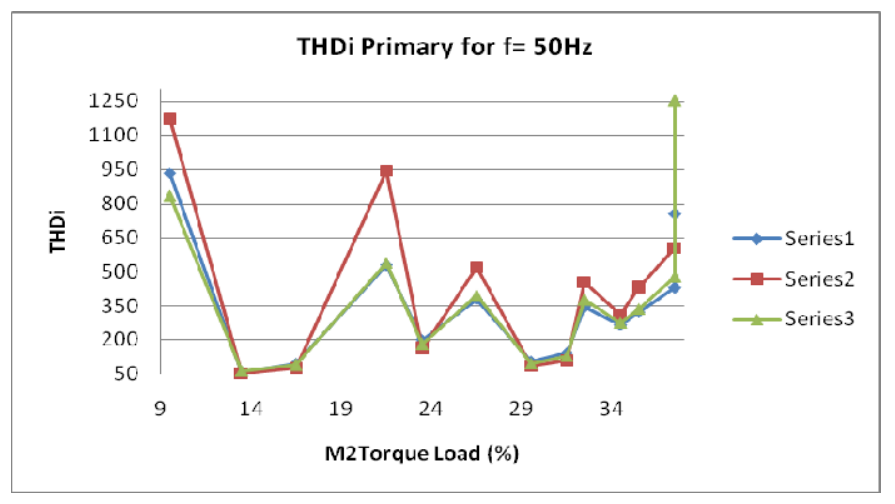

Fig. 8. THDi vs M2 torque load at point $\mathrm{C}$ for M1 at $25 \%$ of rated torque. 


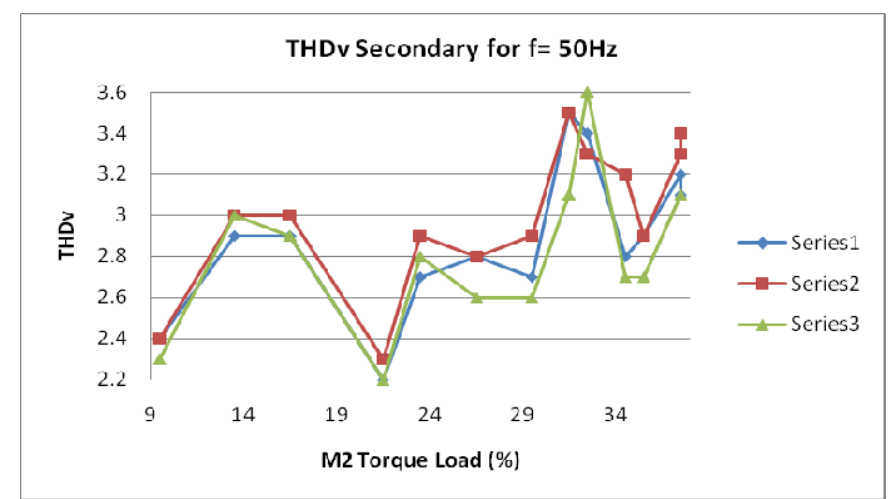

Fig. 9. THDi vs M2 torque load at point D for M1 at $25 \%$ of rated torque.

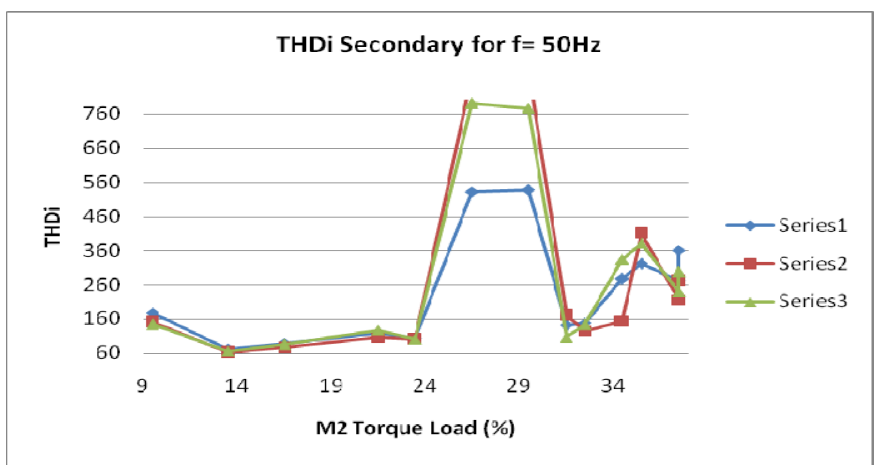

Fig. 10. THDi vs M2 torque load at point $\mathrm{D}$ for $\mathrm{M} 1$ at $25 \%$ of rated torque.

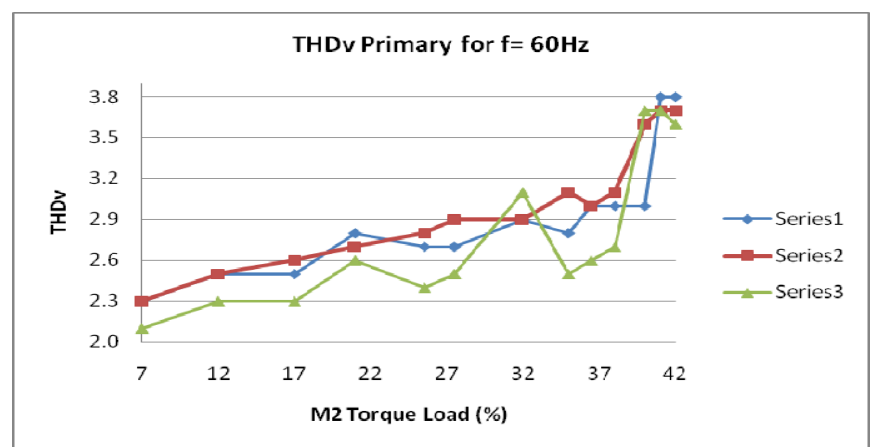

Fig. 11. THDi vs M2 torque load at point $\mathrm{C}$ for $\mathrm{M} 1$ at $25 \%$ of rated torque.

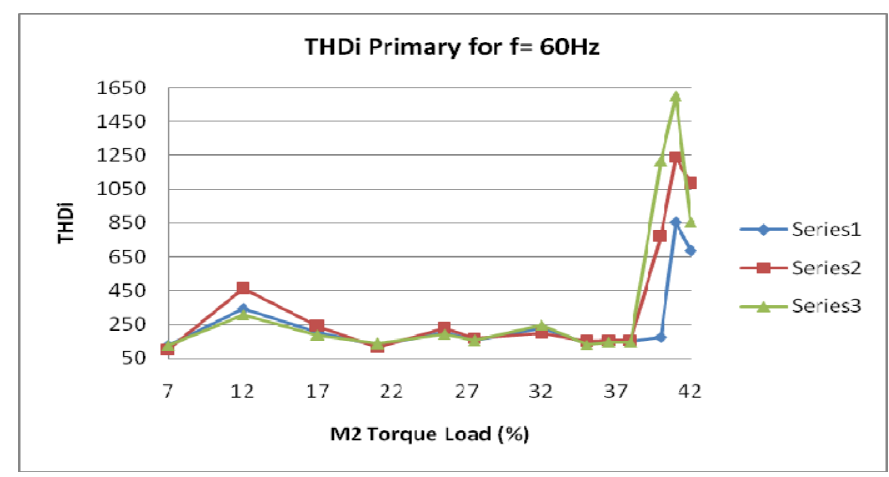

Fig. 12. THDi vs $\mathrm{M} 2$ torque load at point $\mathrm{C}$ for $\mathrm{M} 1$ at $25 \%$ of rated torque.

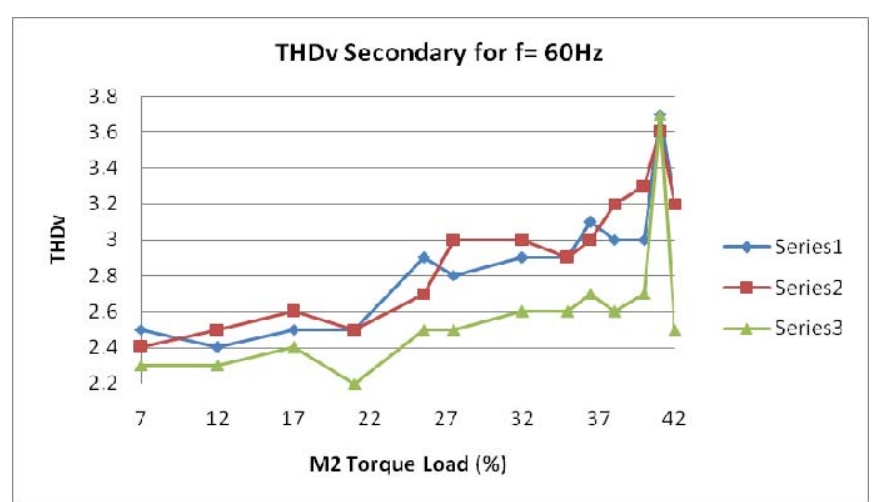

Fig. 13. THDi vs M2 torque load at point $\mathrm{D}$ for $\mathrm{M} 1$ at $25 \%$ of rated torque.

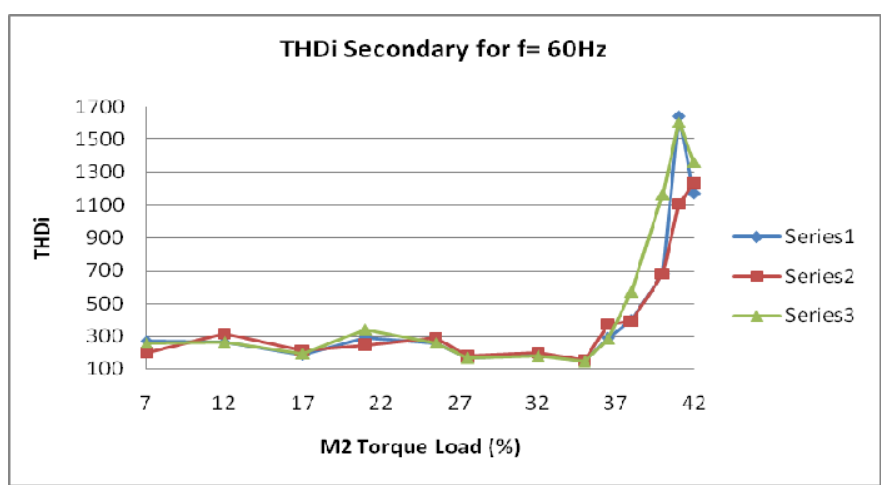

Fig. 14. THDi vs M2 torque load at point D for M1 at 25\% of rated torque.

\section{CONCLUSIONS}

The analysis of the data shows trends in the harmonics behavior in the grid-connected photovoltaic system with adjustable speed drives as loads and can be used to analyze power quality in a system with similar components and setup. Optimum operation condition based on the worst and best case operating scenarios was determined and identify.

Worst case in this project was determined and identified when the system had to change the energy supply from PV to grid. At condition when system nearly changes the supply, THDi has the higher value. On the other hand, the best case happened when energy supply from PV is strongly used rather than grid.

\section{REFERENCES}

[1] F.L. Albuquerque, A.J. Moraes, G. C. Guimarães, S. M. R.Sanhueza, A. R. Vaz, "Optmization of a photovoltaic system connected to electric power grid", Proc. IEEE/PES Transmission \& Distribution Conference \& Exposition: Latin America, 2004, pp. 645-650.

[2] R. Foster, "Photovoltaic markets and applications", Southwest Technology Development Institute, New Mexico State University, March 15, 2007.

[3] C. Mitsui, S. Tu, Taufik, and M. Anwari, "Efficiency study of adjustable speed drive with dual motor connection," Proc. IEEE International Power Engineering Conference (IPEC), 2007.

[4] Taufik, Erin Matsumoto, Makbul Anwari, "Impact of multiple adjustable speed drive system to power system harmonics" Proc. $2^{\text {nd }}$ IEEE International Conference on Power and Energy(PECon 08), December, 2008.

[5] F. Jurado, N. Acero, A. López, J. I. Rojas, “Adjustable speed drives and voltage stability", Proc. International electric machines and drives conference 2001, pp. 522-527. 


\section{BIOGRAPHIES}

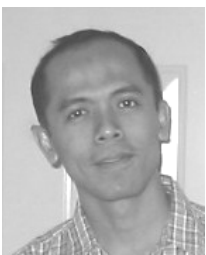

Makbul Anwari (S'2004-M'2006) was born in Pontianak, Indonesia. He received the B.Eng. degree in Electrical Engineering from University of Tanjungpura, Indonesia, in 1995, the M.Eng. degree in electrical engineering from Bandung Institute of Technology, Indonesia, in 2000, and the Dr.Eng. degree from Nagaoka University of Technology, Japan, in 2005. From 1995 to 2006, he joined the Electrical Engineering Department at University of Tanjungpura, Indonesia, where he was a Lecturer. Currently, he is a Senior lecturer at the Department of Energy Conversion Engineering, Faculty of Electrical Engineering, Universiti Teknologi Malaysia. Dr. Anwari is a member of the IEEE Power and Energy Society and Industry Application Society.

Muhammad Imran Hamid received the M.Eng. degree in Electrical Engineering from Bandung Institute of Technology in 2001. Currently, he is a $\mathrm{PhD}$ candidate at the Department of Energy Conversion Engineering, Faculty of Electrical Engineering, Universiti Teknologi Malaysia.

Muhammad Ikram Mohd Rashid received the B.Eng. degree in Electrical Engineering from Universiti Teknologi Malaysia in 2008. Currently, he is a master student at the Department of Energy Conversion Engineering, Faculty of Electrical Engineering, Universiti Teknologi Malaysia.

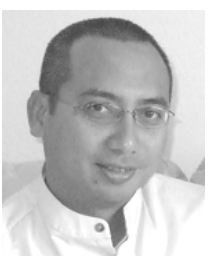

Taufik (M'1997, SM'2007) was born in Jakarta, Indonesia. He received his BSEE degree with minor in Computer Science from Northern Arizona University in 1993. He then continued his study and received his MS degree in Electrical Engineering and Computer Science from the University of Illinois at Chicago in 1995. Following this, he spent one year working as a research assistant at the Microelectronics Fabrications lab at the University of Illinois at Chicago before pursuing his Doctoral degree in electrical engineering at Cleveland State University which he received in 1999. Since then, Dr. Taufik joined the Electrical Engineering Department at California Polytechnic State University in San Luis Obispo where he is currently a Professor.

Dr. Taufik has had industrial experience working with engineering companies such as Capstone Microturbine, Picker International (currently Philips Medical System), Allen-Bradley (Rockwell Automation), Rantec Power Systems, San Diego Gas \& Electric, and APD Semiconductor (currently Diodes Inc.). Dr. Taufik's main areas of interests are in power electronics and engineering education. 